\title{
DESCARTES Y EL PERIODISMO DE ESTADISTA. UNA INTERPELACIÓN A VARGAS Y A LA OPINIÓN PÚBLICA INTERNACIONAL (1951-1953) ${ }^{1}$
}

\author{
Descartes e o Jornalismo de Estadista. Uma interpelação a Vargas e à opinião \\ pública internacional (1951-1953)
}
Descartes and Statesman Journalism. The interpellation with Vargas and international public opinion (1951-1953)

César Luis Díaz

Profesor de la Universidad Nacional de La Pata, Argentina tatodiaz60@gmail.com

\section{Resumen}

El presente artículo se propone demostrar, a partir de la noción de "periodismo de estadista", la estrategia discursiva desarrollada por Descartes en el diario Democracia (1945-1955). El seudónimo fue utilizado por el presidente argentino, Juan D. Perón entre los años 1951-1953, para generar conciencia en la opinión pública internacional y en su par Getulio Vargas, sobre la trascendencia de llevar adelante el proyecto del ABC. Además se explorarán diversos aspectos periodísticos vinculados con el diario Democracia, Descartes y la columna de opinión "Política y Estrategia (No ataco, critico"). Así como también, la participación de João B. Lusardo y Geraldo Rocha, personas de estrecha confianza de Vargas y Perón.

Palabras clave: Perón/Descartes. Periodismo de estadista. Vargas.

\section{Resumo}

O presente artigo pretende demonstrar, a partir da noção de "jornalismo estadista", a estratégia discursiva desenvolvida por Descartes no jornal Democracia (1945-1955). O pseudônimo foi usado pelo presidente argentino Juan D. Perón entre 1951-1953, para aumentar a conscientização da opinião pública internacional e de seu colega Getulio Vargas, sobre a importância da realização do projeto $\mathrm{ABC}$. Além disso, serão explorados vários aspectos jornalísticos relacionados ao jornal Democracia, Descartes e a coluna de opinião "Política e estratégia (não ataque, critico"). Além da participação de João B. Lusardo e Geraldo Rocha, pessoas de grande confiança de Vargas e Perón.

Palavras-chave: Perón / Descartes. Jornalismo de estadista. Vargas.

\section{Abstract}

This article sets out to demonstrate, based on the notion of "statesman journalism", the discursive strategy developed by Descartes in the newspaper Democracia (1945-1955). The pseudonym was used by the Argentine president, Juan D. Perón between the years 1951-1953, to raise awareness in international public opinion and in his peer Getulio Vargas, about the importance of carrying out the $\mathrm{ABC}$ project. In addition, various journalistic aspects related to the newspaper Democracia, Descartes and the opinion column "Politics and Strategy (I do not 
attack, criticize") will be explored. As well as, the participation of João B. Lusardo and Geraldo Rocha, people of close trust from Vargas and Perón.

Key words: Perón / Descartes. Statesman Journalism. Vargas

\section{INTRODUCCIÓN}

Es sabido que la labor periodística, al menos en la Argentina, ha posibilitado el acceso a las más altas magistraturas nacionales a quienes lo ejercieron, sobre todo, en el siglo XIX. Sin embargo, solo dos presidentes asumieron tareas periodísticas mientras se desempeñaron como primeros mandatarios, en el siglo XIX, Domingo F. Sarmiento (1868-1874) y, en el siglo XX, Juan D. Perón (1946-1955)². En tanto, otros mandatarios lo hicieron antes y/o después de ocupar la primera magistratura, pero no en forma simultánea.

$\mathrm{El}$ interrogante que orienta este estudio es explorar las razones que habría tenido el presidente Perón para escribir semanalmente las columnas firmadas bajo el seudónimo de Descartes en el matutino Democracia. Así se indicará el por qué utilizó ese apelativo, también se precisará los motivos por los cuales comenzó a escribir en un diario de circulación masiva $\mathrm{y}$, por supuesto, se conjeturará los motivos de su alejamiento de la columna periodística. Para ello, se cuenta con la totalidad del corpus, con la particularidad que, en este caso, se ha recurrido directamente a Democracia y no a las recopilaciones efectuadas ${ }^{3}$. Por este motivo se podrá aportar algunas apostillas acerca de los días que aparecía, en qué ocasiones se adelantó, e incluso, la causa excepcional para que en una oportunidad no apareciera. Asimismo, se reseñará las repercusiones obtenidas, la columna firmada por el curioso seudónimo en la prensa extranjera. También se recuperará por primera vez el diálogo público sostenido por Descartes y el director del medio. Todo desde la noción analítica de "periodismo de estadista" que da cuenta del desempeño periodístico de los presidentes de la nación durante el ejercicio del poder.

A propósito de la categoría de análisis que aquí se propone, se considera que se da el "periodismo de estadista" - en la gráfica ${ }^{4}$ - cuando el responsable de la columna de opinión, quien a menudo la rubrica con un seudónimo, se halla en ejercicio del poder Ejecutivo del país. Naturalmente, colaboraciones periodísticas de esta índole no reciben remuneración alguna y la efectúan en un diario o periódico cercano ideológicamente al autor.

Con relación al tenor de las notas firmadas, se debe resaltar que poseen trascendencia política para el país de su autor y/o se trata de sentar un precedente político para el público nacional o internacional. En este punto, se debe consignar que no siempre las columnas son portadoras de intereses partidarios y/o nacionales, pues también suelen contener objetivos 
meramente personales del estadista firmante y bien pueden constituir colaboraciones ocasionales y sin un eje vertebrador o, por el contrario, puede tratarse de una saga o serie con un claro objetivo político -nacional y/o internacional-. En otros términos, el comunicador presidencial puede responder a cuestiones de terceros o bien proponer líneas a seguir. Por último, se debe dejar en claro que los artículos intentan formar opinión en sintonía con la política trazada desde el núcleo duro del poder. Este público puede no saber a quien responde el seudónimo que acompaña los sueltos.

\section{EL DIARIO}

Democracia fue fundado el 3/12/1945, para captar votos de los sectores medios argentinos en las elecciones del 24/2/1946 que consagraron a Perón como presidente. Se sabe que éste contaba con el favor de la clase obrera representada por el Partido Laborista. El diario estuvo dirigido en sus comienzos por Molinari, Birabent y Estrada, quienes se hallaban consustanciados por las ideas enarboladas por el hombre fuerte de la Revolución del 4/6/1943. Una mirada poco complaciente con el sistema de comunicación peronista sostiene que: "Democracia se identificaba así mismo como un diario liberal independiente, durante la campaña electoral su tono fue mucho menos sicofante que el de los otros diarios peronistas" (PLOTKIN, 1993, p. 326).

El gobierno compró en noviembre de 1946, la empresa, por diferencias políticas y, sobre todo, por la no viabilidad de su proyecto periodístico, e influida por su desatino en el manejo financiero. "Esta primera obtención en el mercado de medios apuntaba a constituir al diario Democracia como el órgano de difusión del gobierno" (PELAZZAS, 2012, p. 40). Eva Perón se convertirá en la titular de la empresa, aunque delegando en terceros las responsabilidades empresariales y periodísticas.

Este traspaso de mano significó para el matutino un incremento enorme en su tiraje y la conversión en "vocero del gobierno peronista". Acaso, este sesgo alcance su máxima expresión en su lema insertado junto al logo del diario, inspirado en una frase de Perón: "Mejor que decir es hacer y mejor que prometer es realizar". Siete años más tarde, tras la muerte de Evita (26/7/1952) se agregó la frase "Mil veces lo volvería a hacer por Perón y por mi pueblo", acompañado por el dibujo de su rostro encerrado en un óvalo (DÍAZ, 2019b).

En cuanto a la orientación periodística fueron cuatro sus responsables hasta la caída del peronismo en 1955. Arístides Zuritta, quien dio el primer impulso, estuvo unos pocos meses entre la transición de los fundadores y Raúl Apold (1947-1949) y, durante el período 
que aquí interesa Martiniano Passo (1949-1951) y finalmente Américo Barrios (1951-1955).

Este poderoso "actor político" convertido en el más importante vocero del justicialismo acompañó los derroteros del gobierno y, sobre todo, la intensa actividad social y política de la Primera Dama, alcanzando el reconocimiento popular como "el diario de Evita", más por su presencia fotográfica e informativa que por ser la dueña. El tabloide fue incorporando secciones - turf, policiales, deportivas -, al tiempo que imprimía un compromiso de mayor grado en sus editoriales, que fueron cambiando de sitio. Durante la dirección de M. Passo se insertaban en la tapa y, bajo la tutela de A. Barrios pasaron a la página 3. Con el tiempo se fueron incorporando otras firmas en la portada (Díaz, 2019a).

\section{ALGUNAS CONJETURAS ACERCA DE LA APARICIÓN DE DESCARTES}

Hasta el presente se ha mencionado la participación de Perón en el matutino, pero nada se ha dicho del por qué, tampoco se ha profundizado demasiado en sus columnas. De forma que se procurará en adelante echar luz sobre las posibles motivaciones que haya tenido Perón para tomar la pluma y participar en la prensa mientras estaba a cargo del Poder Ejecutivo. Se dirá por ahora que la participación periodística de Perón podría obedecer a varios factores concomitantes: la nueva llegada al poder de Getulio Vargas (1951-1954) en el Brasil, la idea prohijada por Perón de la Unidad Sudamericana -con sus dos pilares, la tercera posición y el ABC latinoamericano- cuestiones que estuvieron bien maduras en enero de 1951, momento en que el presidente Perón entró en la arena periodística.

Antes que nada, se deben apuntar ciertos aspectos de la política exterior de la Argentina que venían desde principio de siglo. El país en ambas conflagraciones mundiales se aferraría al "neutralismo", rompiéndose esta situación en marzo de 1945 cuando todo estaba resuelto. Una vez producido el 17 de octubre irrumpió en el escenario político el embajador de los EEUU, Spruille Braden, encabezando la oposición al candidato Juan Perón. Tal fue la hostilidad del funcionario norteamericano que se ideó la consigna "Braden o Perón” para las elecciones. Una vez en el poder, la administración justicialista, buscó a través de la llamada tercera posición establecer una nueva inserción internacional del país en el mundo bipolar. Esta postura pretendió contrarrestar, de algún modo, el peso considerable de los EEUU procurando un mayor protagonismo en América Latina. Pero consolidando la tradicional conexión con Europa y estableciendo vínculos diplomáticos con las naciones detrás de la "cortina de hierro", aunque sin que esto significase abandonar la alineación con Occidente. 
En el ámbito diplomático, el peronismo debió enfrentar el hostigamiento de ciertos sectores predominantes de Washington y de la opinión pública estadounidense. Perón para neutralizarlo, intentó contemporizar los vínculos diplomáticos a través de sus buenas relaciones con el embajador Messersmith -sucesor de Braden- y con diversos gestos de acercamiento, conjuntamente con la intensificación del comercio bilateral. No obstante, las divergencias siguieron existiendo, aumentadas de ambos lados por la gravitación, tanto del periodismo estadounidense, como del argentino.

La tercera posición se presentó "oficialmente" el 6 de julio de 1947, cuando el presidente argentino dirigió un mensaje a todos los pueblos del mundo, por medio de más de 1.000 radioemisoras (entre ellas, la BBC de Londres), proponiendo objetivos de cooperación económica y de paz mundial, desechando los extremismos capitalistas y totalitarios, fuesen éstos de derecha o de izquierda. Puntualizando además que, "para lograr la paz internacional debe realizarse sobre la base del abandono de ideologías antagónicas y la creación de una conciencia mundial de que el hombre está sobre los sistemas y las ideologías, no siendo por ello aceptable que se destruya la humanidad en holocausto de hegemonías de derecha o de izquierda". (Chávez, 1985, p. $10)$.

Esta idea del presidente argentino ha tenido las más dispares apreciaciones, entre las críticas mencionaremos la sostenida por A. Whitaker quien definió a la política peronista de tercera posición en el plano internacional como la búsqueda de aumentar el "poder de regateo" o, más aún, la "posibilidad de negociar" con propósitos nacionalistas, aprovechando la ruptura Este-Oeste y balanceando el peso de las relaciones con EEUU a través de los vínculos con "potencias no americanas" (RAPOPORT; SPIGUEL, 1994, p. 35). Conforme la valoración del embajador Llambí (1997, p. 244): "Perón desarrollaba la iniciativa tal vez más audaz de toda su política internacional. Preparada cautelosamente, rodeada de discreción, fue dando los pasos necesarios a lo largo de varios años, para llegar a su objetivo".

Naturalmente, enarbolar esta política enfrentaba al panamericanismo encabezado por los EEUU, por ende, provocaba al presidente argentino serios contratiempos, más aún que desde Buenos Aires se impulsaba lo que se dio en llamar el "panlatinoamericanismo". Actitud que ha recibido cuestionamientos -no siempre compartibles-, por parte de investigadores. Uno de ellos Zanatta (2013, p. 213) ha llegado a sostener que había una pretensión argentina de encabezar un "imperialismo panlatinoamericano, afirmando que la tercera posición era la doctrina a través de la cual se expresaba el 'destino manifiesto' de los argentinos”.

En tanto, Boholasvsky (2016, p. 173) ha apuntado que la latinidad católica sería la vía 
alternativa a la tensión de la guerra fría:

\begin{abstract}
la asunción de esa 'tercera vía' internacional era inseparable de la aceptación del liderazgo americano, cuando no universal, del propio Perón. Esa pretensión desmesurada de convertir a la Argentina en la locomotora del mundo latino chocó desde ya con el modelo panamericano alentado por Washington -seguido de cerca por Itamaraty-.
\end{abstract}

\title{
4 EL LÍDER BRASILEÑO: GETULIO VARGAS
}

No son pocos los que sostienen que nada influyó más en Perón que su percepción de la experiencia Varguista de los años 30. Generalmente piensan muchos en ejemplo transoceánicos, yo creo, afirma Methol Ferré (2015, p. 40) que Perón tuvo un modelo en Vargas, quien produjo la irrupción del nacional populismo industrializador en Brasil. Incluso fundó el Ministerio de Trabajo. De ahí que vienen asesores brasileños, a la Argentina pedidos por Perón a Vargas.

El presidente brasileño iniciaría la utilización sistemática de los medios de comunicación desde el poder, basándose en el uso de la propaganda para la construcción de su legitimidad política. Durante su primer gobierno, se crearía el Departamento de Propaganda y Difusión Cultural. Desde allí, bajo la dirección del periodista Lourival Fontes, se vertebraría la construcción de un relato nacional que exaltaba la figura del presidente como "padre de los pobres". Sin embargo, el líder popular, conforme el juicio de A. Goldstein (2017) tuvo en el matutino O Estado de S. Paulo y en el vespertino O Globo, dos tenaces opositores.

Se debe recordar que el hombre de São Boja había impulsado la participación del Brasil en la segunda guerra Mundial formando parte del bloque de los aliados. Posición que no debe extrañar pues como afirma Carneiro (1978, p. 441) Brasil desde la independencia tenía estrechos vínculos con los EEUU y, precisamente, luego del ataque japonés en Pearl Harbor (7/12/1941) es cuando se suma a la contienda. Por supuesto que Vargas tuvo operadores de prensa que desde su candidatura tejieron y/o sostuvieron estrechos vínculos con la Argentina, como Geraldo Rocha. Así lo afirma Goldstein (2017b, p. 10),

\footnotetext{
Rocha participaría en los actos de la campaña presidencial de Vargas en 1950, perteneciendo al círculo íntimo del ex dictador, junto con Juan B. Lusardo y el periodista Samuel Wainer. Lusardo y Rocha conformaban una especie de sociedad común en su representación del gobierno de Vargas frente al peronismo.
}

La campaña presidencial del riograndense fue "monitoreada" por los medios opositores en ambos países. En la Argentina, La Nación expresaba: 


\begin{abstract}
Informaciones no confirmadas que circularon esta noche en Río de Janeiro, dicen que el presidente de la Argentina, General Perón, vendrá en breve al Brasil, en forma extraoficial para hacer una visita privada al Dr. Getulio Vargas. Dichas informaciones señalan que Vargas recibirá al general Perón en San Pedro, cerca de la frontera argentina, en el Estado de Río Grande del Sur, donde se encuentra esperando el resultado final de las elecciones, en la estancia del ex embajador brasileño en la Argentina, Sr. Baptista Lusardo. ${ }^{5}$ Entrevistado en su estancia por un periodista, Lusardo declinó afirmar o negar las informaciones sobre la posible visita del general Perón (9/10/1950).
\end{abstract}

Claro está que para los medios que simpatizaban con el gobierno en la Argentina la noticia del triunfo de Vargas obtenía repercusiones distintas. Democracia, por caso, poseía aún más motivos para alegrarse y lo compartía con sus lectores al publicar en su primera plana una foto del presidente "gaúcho" con su firma, con una bajada que informaba: "Vargas que asume hoy la presidencia de Brasil, materializando las esperanzas de los trabajadores de su patria, ha dedicado esta foto a DEMOCRACIA" (31/1/1951).

En síntesis, compartiendo conceptos de Ferré, se puede aseverar que: "así como la política de planificación y de meta que inicia Perón va a repercutir en el Vargas de la presidencia de 1951. Hay una interacción mutua primero de Vargas sobre Perón y, luego, de Perón sobre Vargas".

\title{
5 EL VECTOR PERONISTA
}

El ABC, proyecto que interesaba a Perón y que, a la vez, incomodaba a otros, se puede calificar como muy sensato a juzgar por la crítica reacción del Departamento de Estado, quien manifestaba:

otra tentativa por parte de Perón de interferir en los planes que tienen los EEUU para desarrollar un sistema efectivo de defensa hemisférica occidental lo constituyeron sus llamados destinados a hacer renacer el grupo ABC. El Presidente argentino sugirió en julio de 1950 la unión de los tres países como una solución a sus problemas' (Rapoport y Spiguel, 1994, p. 281).

Más arriba observamos cómo Perón había instalado el tema de la tercera posición, pero de forma oficial y pública. Con todo se debe reparar también, en la estrategia que tuvo para de a poco y, con diversos sectores ir sugiriendo la necesidad de tener una política propia en el contexto de la incipiente "guerra fría".

El 24/11/1946, en una crónica de La Nación se lee que Perón dirigió un mensaje a los trabajadores en el Teatro Colón, allí manifestaría: "los partidos totalitarios realizaban toda su obra para la guerra y nosotros estamos realizando toda nuestra obra para la paz" alegando a continuación que su movimiento rechazaba tanto el "régimen capitalista" como el "estatal 
puro". También habló de un nuevo sistema, que "hemos de ir tanteando empíricamente para entrar en él”. Un par de días después, esta vez interpelando al sector industrial refirió que el mundo marcha en su cruda evolución hacia nuevas formas para expresar taxativamente: “parecería que una tercera concepción pudiera conformar una solución aceptable, por la cual no se llegaría al absolutismo estatal, ni se podría volver al individualismo absoluto del régimen anterior" (LN, 26/11/1946).

Esta política exterior tenía un pilar fundamental en el sur del continente, de modo que, también había que construir una base sólida para la unidad. A solo 6 meses de su asunción, el gobierno argentino firmaba con Chile el acuerdo del 12 de diciembre de 1946, por el que se liberaba de derechos aduaneros a los productos de ambos países, a través de un régimen de cupos y listas de excepción, de modo de proceder gradualmente hasta la liberación total. En realidad, Perón tampoco descuidaba al gigante sudamericano y el 21/5/1947 - durante la presidencia de Eurico G. Dutra - en Uruguayana argumentaba en un discurso:

No puede hablarse de las historias de nuestras patrias, sino de una sola historia. Tampoco puede hablarse de impulsos nacionales sino de un solo impulso americano, porque estos y aquella, sin desconocer los fuertes valores de ambos pueblos, han sido siempre un solo y feliz camino hacia el porvenir (FERNÁNDEZ BARAIBAR, 2005, p. 88).

Esta tesitura se mantuvo con sus más y sus menos, afianzándose hacia los años '50. Momento en el cual Vargas procuraría retomar el gobierno del Brasil, situación que Perón juzgaba trascendental para sus planes. De forma que era pertinente reajustar las acciones, por caso, las de dos de sus más grandes amigos/políticos brasileños -Joao B. Lusardo y Geraldo Rocha- con el fin de colaborar para el regreso de Vargas al poder. Así como también que fueran los nexos para una reunión entre los dos líderes.

\section{LUSARDO EL EMBAJADOR DE LA "BUENA VOLUNTAD"}

Lusardo se había desempeñado en dos oportunidades como embajador en nuestro país, e incluso se lo sabía amigo de Perón y Evita. Con relación a Vargas tuvo un papel crucial en la campaña y fue tan estrecha la amistad entre ambos que, Getulio se alojaría en la hacienda que Lusardo poseía en Uruguayana durante todo el proceso eleccionario. A pesar de la cercanía personal y política con Vargas, a éste no le fue sencillo nombrar a su amigo como embajador en la Argentina, pues la oposición del partido de la Unidad Democrática Nacional y el propio titular de Itamaraty, Joao Neves da Fontoura se negaban a dar la aprobación (Carneiro, 1978). 
Tras interminables gestiones Lusardo logró ser el representante en Buenos Aires. De esta forma se habría una gran esperanza para la consecución de la monumental jugada geopolítica ideada por Perón. En efecto, Lusardo estaba totalmente consustanciado con el ABC y se convertiría en un gran nexo -pero no el único- entre ambos presidentes. De hecho, el líder justicialista a poco de la llegada de Lusardo a Argentina, por tercera vez, plantea en el banquete que ofrece al embajador recién llegado:

\begin{abstract}
deseo que en estas breves palabras llegue mi profundo agradecimiento al ilustre amigo, presidente de los brasileños, Dr. Getulio Vargas, agradecimiento que de corazón le hacemos llegar los argentinos [...] los deseos y el entendimiento que ese porvenir depara a los argentinos y brasileños [...] para que esa indivisible unidad del destino futuro de estas tierras sea una realidad, estamos trabajando aquí como estamos trabajando allá. Lusardo, como laso de unión que ennoblece la acción que realiza, es el embajador ideal para comenzar una tarea quizás muchas veces pensada [...] haremos y realizaremos esta unidad indestructible que es hoy esperanza de argentinos y brasileños. (FERRÉ, 2015, p. 80).
\end{abstract}

Con todo, la labor del diplomático brasileño (15/8/1951 - 30/10/1953) se fue desdibujando conforme transcurría el tiempo, pues no lograría convencer a su presidente que se reuniera con el mandatario argentino. Mientras tanto otro emisario asumía el papel de interlocutor y lo hacía desde su doble rol: de periodista y amigo de ambos jefes de Estado.

\title{
7 GERALDO ROCHA EL "JAGUNÇO"
}

El concepto ha sido recuperado por Goldstein $(2017 b$, p. 8$)$ y significa "protector del hombre fuerte" y, Rocha, ejercía ese rol desde sus empresas periodísticas el diario O Mundo y las revistas O Mundo ilustrado y O Mundo Agrario. Desde estos dispositivos gráficos - que no fueron los únicos $-^{6}$ se realizaría una propaganda abierta y sistemática del peronismo en Brasil, buscando el acercamiento entre Perón y Vargas, generando el rechazo de la prensa brasileña tradicional, alineada con la política panamericana de EEUU. "Sus publicaciones alertarían también a medios norteamericanos como el New York Times, que señalaban a Rocha como 'el único' brasileño que siempre se refiere afablemente sobre el General Perón” (GOLDSTEIN, 2017b, p. 13).

Con posterioridad y ante la negativa de Vargas de encontrarse personalmente con Perón y no suscribir el acuerdo comercial con el Chile de Ibáñez, se fue desvaneciendo la idea del ABC. A tal punto que en ocasión de devolver la visita el mandatario trasandino a Perón, en junio de 1953, el diario del jagunço ilustraba la crónica con una foto en la que se veían los dos mandatarios y Geraldo Rocha, lo que constituía todo un símbolo dada la ostensible ausencia del presidente brasileño. 
Evidentemente, la renuencia al encuentro personal por parte de Vargas ${ }^{7}$ influyó, decididamente en la política exterior justicialista que tomaría "Nuevos Rumbos".

\title{
8 DESCARTES PORTAVOZ DEL "PERIODISMO DE ESTADISTA"
}

Resulta extraño que a comienzos de la década del '50, un diario de tirada masiva, una vez a la semana, insertara un artículo con un título permanente "Política y Estrategia. (No ataco, critico)" firmado con el seudónimo Descartes. Sin embargo, para el periodismo argentino este caso reviste todavía mayor importancia, pues permite comprender mejor la política exterior de Perón y, lo más importante, conocer cómo Descartes buscaba crear una consciencia política en sus lectores - tanto nacionales como internacionales -. Elevar su conocimiento de estas temáticas y convertirlos en impulsores de estas políticas.

A propósito del seudónimo se retomará lo expresado por Díaz (2019a, p. 12) al recordar las propias palabras de Perón: "Si Descartes firmaba como Perón, ¿por qué Perón no va a firmar como Descartes?". A modo de ejemplo se mencionarán dos referencias al apelativo, una negativa y otra positiva, no mencionadas en el trabajo citado.

Con relación a la primera, Zanatta (2013, p. 280) aseveraba con tono crítico:

\begin{abstract}
se dieron cuenta los diplomáticos acreditados en Buenos Aires de la intoxicación que, como tiempo atrás, estaba causando la tercera posición. El mejor ejemplo de ello fue la larga serie de artículos firmados por Descartes que empezó a publicar el diario Democracia. El motivo no podía ser más obvio: tras el seudónimo se ocultaba el propio Perón.
\end{abstract}

La segunda pertenece a quien se desempeñó como canciller en este período (19491951) y elaboró una definición más cercana y precisa al novel comunicador: "Perón era un racionalista. La estructura de su pensamiento, cartesiano. No porque sí eligió el seudónimo de 'Descartes' para firmar los artículos que escribía por los años 50', para el diario Democracia" (Paz, 1999, p. 153). Se debe acotar que la rúbrica que acompañaba a las columnas constituyó un gran interrogante para el ámbito político/ comunicacional/ diplomático del momento, incluso le llevaría un buen tiempo al Departamento de Estado saber a quién pertenecía el seudónimo. Cuestión que fue esclarecida recién en mayo de 1951.

Lo cierto fue que, a juzgar por las repercusiones obtenidas, se revelaría como una eficaz estrategia interpelar a los lectores, sobre todo, a los extranjeros, desde la primera plana de un diario. Efectivamente, publicaciones de Chile, Brasil, Ecuador a menudo reproducían los textos cartesianos. En el caso de la Revista Voz de México efectuó un penetrante comentario al apuntar: 


\begin{abstract}
'Descartes' no teoriza, ni ataca, ni incurre en excesos imaginativos. La objetividad de sus comparaciones históricas constituye una disciplina ejercida en el sentido de evidenciar ordenadamente las aberraciones, las falsedades, y todo aquello que puede servir para 'deshacer entuertos'. Su Crítica no es derrotista o producto de un estado bilioso patológico; es constructiva. Por sobre todas las cosas, llama a la concordia y a la comprensión mutua. Sus expresiones denotan una mente perfectamente centrada, impermeable a las corrientes idearias comunes, a las que pueden atribuirse muchas de las dificultades que deben los pueblos soportar (DEMOCRACIA, $8 / 5 / 1952)$
\end{abstract}

Reflexiones como esta eran jerarquizadas en los sitios privilegiados del impacto visual, con el fin de ponderar al singular colaborador y, por lo tanto, al diario.

En rigor, el medio apelaba a diversos recursos para captar la atención de la amplia gama de lectores que esperaban jueves tras jueves la sugerente columna. Así, fue que, el diario compartió un diálogo público en sus páginas entre el director A. Barrios y el incógnito comentarista. Este último, tras devolver los saludos ofrecidos por el director de Democracia en una epístola privada, expresaba:

\begin{abstract}
correspondiendo a los conceptuosos términos con que Ud. califica mis trabajos publicados, es grato hacerle saber que en mérito de ellos - si es que alguno tiene - se debe a la imparcialidad del juicio emitido, acerca de los problemas creados a todos los países por la situación actual, sin ocultar el pensamiento que sugiere la contemplación del futuro, que es lo único previsible y lo que más debe preocupar, por eso, a los pueblos del mundo.
\end{abstract}

En estas líneas más coloquiales transparentaba, igualmente, su inquietud de estadista, oculto tras un apelativo, al enfatizar la incertidumbre que atravesaban las naciones que pugnaban por su soberanía. Aprovechaba, por lo demás, la ocasión para comprometerse a continuar con su labor periodística. En la misma página Barrios dejaba correr su pluma para expresar:

Los comentarios de Descartes tienen trascendencia histórica. Todos los jueves, como continuará siéndolo en adelante, su palabra monitora contribuyó en medida sin tasa a esclarecer y orientar la opinión no solo del país sino de América y aún del mundo. Lo atestigua la basta repercusión que ella tiene en nuestro ámbito como en el exterior, donde ha sido y es traducida y retransmitida de inmediato en todos los idiomas y a las más distantes latitudes.

Razonamientos que no eran exagerados tal cual se podía verificar en las páginas del diario.

El contacto directo con el corpus ha posibilitado detectar algunos detalles vinculados con las notas de Descartes. Estas comienzan el miércoles 24/1/1951 a solo 6 días de que asumiera Vargas la presidencia. Posteriormente, casi siempre se publicaron los jueves en la primera página, con dos salvedades dignas de ser remarcadas. La primera que el jueves 
1\%/1952 la columna no se publicó por la muerte de Evita que ocupaba gran parte de la superficie redaccional. La segunda excepción fue el jueves 7/8/1952 porque continuó la cobertura periodística de los funerales de la primera dama argentina insertándose, por única vez, en la página 3 junto al editorial.

\section{EL "PERIODISMO DE ESTADISTA” EN ACCIÓN}

Como se ha observado anteriormente Perón no había escatimado esfuerzos en inculcar por los medios a su alcance -discursos, conferencias, emisiones radiales, etc.- la necesidad de que las naciones del Sur se unieran, con la finalidad de amortiguar el poderío de los EEUU. En 1950 y con el triunfo de Vargas, creyó impostergable redoblar la prédica y asumió la responsabilidad de transmitir sus inquietudes a través de la prensa. Sabía que no había tiempo que perder pues la "guerra fría" y el panamericanismo conspiraban contra la "Unión suramericana".

Sin embargo, el presidente argentino no podía ni debía excederse en su prédica anti imperios, pues su investidura desaconsejaba subir el tono de las críticas para no comprometer aún más sus objetivos políticos. Pero, si la misión la efectuaba un alter ego periodístico, con la amplificación natural que proporciona la prensa escrita y la posibilidad de construir sentido a favor de la necesidad de que la región adoptara políticas de integración, la tarea se potenciaría.

De ahí que, Descartes desplegará una serie de estrategias para construir lo que se ha denominado el "panlatinoamericanismo". Con tal objeto acometería con su labor persuasiva hacia las "naciones hermanas" y con denuncias de injerencias imperialistas. Esta temática ha sido desarrollada en dos ejes basados en la denuncia del imperialismo y su herramienta más eficaz que fue la "propaganda" (Díaz, 2019a). De forma que aquí el estudio avanzará haciendo hincapié en la construcción discursiva sostenida por Descartes frente a la imperiosa necesidad de sumar a Brasil a la consolidación de un bloque continental, como así atraer a toda latinoamerica a la empresa.

En el recorrido por la serie de colaboraciones de Descartes se observa que posee un eje vertebrador: la Unión del Sur. Comienza centrando la atención en la "guerra fría", sus protagonistas y el rol trascendental que juega la comunicación en ello:

los hombres proceden tan bien como estén de bien informados. Una situación equivocada conduce a errores en la apreciación y en los hechos. Por eso, en la conducción política internacional la penetración de los problemas y su comprensión son la base de todo" (29/3/1951). 
Conforme pasa el tiempo, se va ajustando el mensaje y al momento de aprobarse las credenciales de Lusardo, embajador político brasileño, Descartes despliega su plan comunicacional puntualizando los tópicos más caros a su política que considera indispensable aplicar al "periodismo de estadista".

Así, a partir de agosto, los temas que se suceden constituyen elementos decisivos para una sólida "construccción discursiva". Por caso el 9/8/1951 escribió:"El movimiento sindical argentino, articulado alrededor de la Confederación General del Trabajo, ha permanecido ausente y prescindente de toda esta lucha engañosa de intereses políticos, manteniendo, como el país, una prudente 'tercera posición'”.

"Los efectos de la guerra" fueron motivo de una columna, en la que se analizaba el Plan Marshall y su resultado negativo para la región (27/9/1951). Luego la centralidad del discurso la asumió, lo que el articulista denominó, "La hora de los pueblos”, basándose en otro vértice de su política/comunicacional:

\footnotetext{
cuando hablamos de una 'comunidad organizada', nos referimos a un gobierno, un Estado y un pueblo que orgánicamente deben cumplir una misión común. Para que ello suceda, es menester primero establecer esa misión, luego ordenarse adecuadamente para cumplirla, disponiendo de una organización objetiva, simple, pero eficaz y estable" (29/11/1951).
}

Por fin, el 20/12/1951 se produjo el punto de inflexión en el estratégico "periodismo de estadista". Descartes desplegaría toda su capacidad persuasiva en la columna "Confederaciones continentales". Allí, con un discurso de fuerte tono pedagógico explicitaría su plan para las naciones donde impera la cruz del sur:

[el] moderno continente latino, está y estará cada día más en peligro. Sin embargo, no ha pronunciado aún su palabra de orden para unirse. $\mathrm{El} \mathrm{ABC}^{8}$ sucumbió abatido por los trabajos subterráneos del imperialismo empeñado en dividir e impedir toda unión propiciada o realizada por los 'nativos' de estos países 'poco desarrollados' que anhela gobernar y anexar, pero como factorías de 'negros y mestizos'.

Continuaba autointerpelándose retóricamente para conferir mayor contundencia a su discurso: "entretanto, ¿qué hacemos los sudamericanos? Vivimos en pleno siglo XIX en el siglo XX, cuando el porvenir puede ser nuestro según las reglas del fatalismo histórico y geográfico, a condición de despertarnos a tiempo". Líneas más abajo esperaba aún, el “corazón" del profundo mensaje, que hallará su absoluta contundencia en la formulación de un apotegma que goza en la actualidad de la perennidad de las frases célebres: "juntos seremos inconquistables. Separados indefendibles". 
Ni bien apareció el artículo, Juan Duarte secretario de Perón, telefoneó a Lusardo para que lo leyera y lo enviara rápidamente a Itamaraty (CARNEIRO, 1978, p. 427). No obstante la apresurada diligencia, Vargas no acusó recibo de la misma. Entonces, Perón decidió como principal alternativa continuar con su estrategia de ejercer el "periodismo de estadista".

Un dato insoslayable es el papel que jugó la embajada estadounidense en la Argentina que, ante la publicación del trascendente artículo, según el "Documento restringido. 1028, Buenos Aires 26/12/1951", notificaba advirtiendo al Departamento de Estado que en el diario Democracia "el 20 de diciembre de 1951, Descartes amplió este tema [ABC] sugiriendo la unión de la Argentina, Brasil y Chile como paso previo a la creación de una confederación Sudamericana que se extendiera hacia el norte, unificando a todos los nacionalismos de origen latino" (Rapoport y Spiguel, 1994, p. 281).

Descartes a pocos días de comenzado el año, citando un discurso de Vargas, analizaba las consecuencias de las medidas económicas/financieras adoptadas en el vecino país (10/1/1952). En la entrega siguiente, asumiéndose como hombre de prensa, denunciaba taxativamente:

\begin{abstract}
con motivo de las últimas publicaciones brasileñas muchos colegas se han preguntado: ‘¿Qué pasa en el Brasil?’. No es fácil contestarse. Aparentemente, sería lo que tantas veces sucede: que un 'pistolero' empresario de publicidad hace mal uso de su instrumento. Pero el pistolero [Assis Chateaubriand] es un irresponsable; detrás de él están los que le pagan, y de ellos los servicios de información y provocación de una potencia extranjera y, aun detrás de éstos, un Departamento de Estado y un gobierno que todos deberíamos reputar como responsable.
\end{abstract}

El articulista intentaba tras la denuncia de la injerencia de los EEUU, provocar una reacción en Getulio: “a los gobernantes de nuestros países se les presenta hoy una disyuntiva de hierro: deben elegir, en lo interno, entre el imperialismo y su pueblo; en lo internacional, entre el imperialismo y sus hermanos de sangre. Nuestro gobierno ya eligió: está con nuestro pueblo y con nuestros hermanos" (17/1/1952).

Una semana después redobló sus esfuerzos y bajo el sugerente título de "Más sobre confederaciones continentales", el presidente/periodista escribió con la firme intensión de que Vargas se sumara a su plan: "la unión latinoamericana no sería obstáculo para una ulterior unidad de toda América, pero sería una garantía para que nuestros Estados la integraran como pueblos libres y soberanos y no como tristes despojos coloniales" (24/1/1952). Por supuesto, la embajada no descansaba y al día siguiente, en otro Documento "restringido", informaba a Washington sumariamente el contenido de la columna escrita por "Descartes"9. 
Transcurridos dos meses -fines de abril-, Descartes, aspiraba atenuar la ola de rumores infundados, acerca del apoyo económico argentino a la campaña del riograndense. Para ello se respaldaba en la publicación de Geraldo Rocha, afirmando que: "cuando surge la popular candidatura de Vargas en el Brasil, conjuntamente aparece la acusación gratuita de que es costeada por el presidente Perón, mientras el diario "O Mundo" publica los documentos que prueban que los oponentes de Vargas reciben dinero de la Standard Oil". Denuncia que no era replicada por la prensa hegemónica brasileña dada su oposición a Vargas.

En las entregas posteriores se fueron alternando distintos temas, el 8/5/1952, abordando los "Pactos bilaterales y la ayuda técnica", Descartes deslizaría una advertencia para Getulio: "si en estos pactos se busca poner unos países contra otros, provocando rivalidades internacionales, se equivocan. Nosotros sabemos cuál es el enemigo común y, si algún gobernante insensato entra en la trampa, estamos persuadidos que su pueblo no lo seguirá en la aventura. ¡Los demás, estamos en claro, no entraremos!”.

El responsable de llevar adelante el "periodismo de estadista", con cierto grado de desaliento en la captación efectiva del presidente brasileño para la causa del bloque austral, intentaba dejar al descubierto para la opinión pública internacional la estrategia instrumentada por el imperio:

\footnotetext{
de un tiempo a esta parte se nos ha hecho un honor inmerecido: cuando los movimientos populares se manifiestan, son acusados de "peronismo". Cuando Getulio Vargas fue postulado para la presidencia del Brasil, los diarios imperialistas lo acusaron de ser un instrumento peronista financiado desde Buenos Aires. Otro tanto dijeron de Chávez en el Paraguay. Velazco Ibarra, en Ecuador, ha sido acusado de lo mismo. La revolución boliviana que llevó a Paz Estenssoro al Gobierno, según el imperialismo y sus secuaces, fue obra del peronismo argentino. En Chile está ocurriendo igual cosa con el general Ibáñez. ¿Cómo no se les ocurriría pensar que son los pueblos? (31/7/1952).
}

Excepto Brasil, las demás naciones firmaron acuerdos con Argentina a partir de 1953.

En adelante la saga enfatizó el tema "justicialismo" vinculado con dispares problemáticas internacionales -prensa, agencias, la idea equivocada de una tercera guerra mundial, etc-. Siempre partiendo desde el concepto de pueblo manifestaba: "los que no estamos con los imperialismos dominantes ni los totalitarismos ideológicos formamos hoy una tercera ideología que nosotros llamamos ‘justicialismo’. En las cuestiones ideológicas, los pueblos cuentan más que los gobiernos, porque estos se sojuzgan, pero los pueblos no". Acaso, Descartes, a pesar de su desaliento respecto a la actitud de Vargas haya pensado en el presidente de Brasil cuando escribió el 28/8/1952: “en el mundo moderno se enfrentan, 
quiérase o no, el internacionalismo y el nacionalismo. Ya no es hora de juzgar, sino de elegir, pero con dignidad".

Sin embargo, ante la falta de una respuesta contundente por parte de Getulio, Perón consideró que Descartes debía abandonar la arena del periodismo. La no incorporación de Brasil daba cuenta de la debilidad de la conformación del bloque sur. De modo que el presidente argentino tendría que continuar la política exterior prescindiendo del "periodismo de estadista”. Decisión que halló su última expresión pública el 11/9/1952. ${ }^{10}$ No por ello, abandonó su idea inicial de la Unión latinoamericana y apoyándose en un diario extranjero, marcaba a fuego una contradicción evidente:

\begin{abstract}
El Washington Post, órgano oficioso de la Casa Blanca, confiesa que la elección del general Ibáñez 'es una derrota de los Estados Unidos'. Nosotros creíamos que la victoria del pueblo chileno era solo una derrota de la oligarquía. La ingenua e inexcusable confesión del Washington Post nos evidencia que los Estados Unidos eran también parte en el pleito político interno de Chile. El mismo diario afirma que fue también una derrota 'la reciente elección del autoritario doctor José María Velazco Ibarra en Ecuador', lo que indica que en esa lucha interna también eran parte.
\end{abstract}

Y Descartes con un fuerte sesgo irónico remataba su idea apelando al refrán que oficiaba de título del artículo,: “convengamos que, como tales, no han tenido mayor fortuna que escrúpulos, pero la intervención en los asuntos internos de otros países se documenta así, por 'confesión de parte', de forma que nos releva de toda prueba".

\title{
10 LA ÚLTIMA CARTA
}

Si bien la desaparición pública de Descartes fue definitiva en este período, no así la de Perón que no se daba por vencido, buscaría otra estrategia en el terreno de la política exterior. Y para llevar adelante su objetivo recurrió nuevamente a su amigo Lusardo, pidiéndole que agudizara su ingenio con la finalidad de conseguir el aval para la firma del tratado con Brasil pues creía relevante mantener informado a Getulio para que no se sintiera desplazado en el plan estratégico. Esta determinación la consideraba decisiva para la unión "pacífico, sur, atlántico" que permitiría a la región equilibrar la relación de fuerza con los EEUU.

A principio del mes de enero de 1953, el mandatario argentino, encomendó al embajador una particular misión. Debía consultar personalmente a Vargas, acerca de qué opinaba sobre la idea de Perón de entrevistarse con el presidente de Chile, Ibáñez, con el fin de firmar un acuerdo entre los dos países (Perón, 1968, p. 94).

Lusardo de inmediato se trasladó en forma secreta a Río de Janeiro, ya había adelantado el 
motivo de su viaje a través de un cable cifrado. En el aeropuerto lo estaba esperando Beijo, el hermano de Vargas, quien lo llevó directamente al palacio presidencial en Catete. Los dos hombres de Río Grande tuvieron una larga entrevista, en la que, según era su costumbre, el presidente brasileño se mantuvo imperturbable, sin dar a su interlocutor la más mínima señal sobre su parecer ante lo que estaba escuchando. Lusardo era un convencido de los beneficios de todo orden que traería para los dos países y para América el entendimiento argentinobrasileño, y sabía que estaba jugando una carta decisiva para las posibilidades del proyecto. Usó todos sus mejores argumentos. Vargas le pidió un par de días para pensarlo. Su respuesta fue positiva ya que no opuso objeciones para que los dos países firmaran el acuerdo, aduciendo que Brasil se sumaría más adelante cuando pudiera resolver algunos asuntos con la oposición política ${ }^{11}$.

Lusardo al llegar a Buenos Aires trasmitió a Perón la "buena nueva" y este puso fecha para su ida al país trasandino. El resto tiene visos de una pesadilla, dado que ni bien se firmó el acuerdo en Santiago, el canciller Joao Neves, desautorizó las declaraciones de ambos mandatarios que dieron por sentado el aval de Getulio al "pacto".

Por supuesto, que cuando Perón arribó a Buenos Aires, sin dilación alguna se entrevistó con Lusardo, quien creía que Neves había actuado sin la anuencia de Vargas. Lo cierto fue que el mandatario argentino perdió la confianza en Lusardo para llevar adelante la misión exitosamente. Mientras tanto, Getulio enviaba a Rocha y a Goulart a conferenciar con Perón.

Evidentemente todos los intentos del presidente argentino fueron en vano, no hubo forma de que Brasil se sumara al proyecto $\mathrm{ABC}$. Quizás esto obedeció a que fue más fuerte el antiperonismo de la opinión pública brasileña, sin descartar la susceptibilidad de Itamaraty; sumada a la desconfianza que despertaba el gobierno justicialista en los militares brasileños, quienes no solo eran pro estadounidenses, sino que fundamentalmente recelaban de que su país se convirtiera en una "república sindicalista" (CARNEIRO, 1978, p. 431). Estas razones distan mucho de la pueril opinión ofrecida por Márquez (2015, p.227), quien argumenta que el acuerdo fracasó porque "al presidente brasileño Getulio Vargas Perón ni siquiera llegó a conocerlo en persona".

Perón cansado de esperar el encuentro con Vargas que nunca se produjo, se limitó a firmar varios acuerdos con Bolivia, Ecuador y Paraguay. Su ansiada unión sur no pudo realizarse, sin embargo, decidió que Descartes hiciera su última participación pública. 
En efecto, Perón luego de recibir la visita del hermano del presidente de los EEUU creyó conveniente apelar una vez más al "periodismo de estadista". Allí se encargó de informar al mundo la decisión argentina de tomar "Nuevos Rumbos" en su política exterior. Tal era el título de la última columna, cuyo discurso procuró sustentar el brusco cambio: "el Dr. Milton Eisenhower tuvo la virtud de disiparlo todo. Una nueva era se inicia en la amistad de nuestros gobiernos, de nuestros países y de nuestros pueblos. Un cambio de política es siempre saludable cuando las finalidades son nobles y elevadas" (30/7/1953). Solo faltaba la postrera explicación que Perón ofrecería en la Escuela Nacional de Guerra, en forma reservada, a un grupo de altos jefes militares argentinos, el 11/11/1953. En esa ocasión haría "pública" las excusas argumentadas por Vargas para firmar el ABC.

\section{A MODO DE CONCLUSIÓN}

En este artículo se ha desarrollado la categoría de "periodismo de estadista" con la finalidad de analizar las colaboraciones de Descartes en el diario Democracia. Se ha podido comprobar que la pluma del presidente Juan Perón era la responsable de las columnas. En la exploración pormenorizada de la serie de artículos importó verificar la verdadera motivación para que un primer mandatario, en uso de sus facultades, ejerciera el periodismo gráfico. En este caso, lo hizo para difundir su pensamiento acerca de la necesidad de que América Latina se uniera -desde el sur- para contrarrestar de alguna manera el poderío que desplegaba los EEUU.

Con relación al período en que Descartes participó se pudo constatar que también fue con el fin de generar en la opinión pública internacional y de modo indirecto en Getulio Vargas, una conciencia favorable para la constitución de un bloque sur. Al mismo tiempo que "Descartes" escribía públicamente, el presidente Perón sumaría a su empresa a, dos colaboradores brasileños, el embajador Lusardo y el periodista Rocha. Con el transcurrir del tiempo, Descartes fue urdiendo una estrategia comunicacional para que la región estuviera informada de los peligros que la acechaban. En diciembre de 1951, creyó propicio el momento para exponer cabalmente su "intensión y publicó "Confederaciones continentales”, con la esperanza de que su par brasileño, dejara de lado sus prevenciones y se atuviera a firmar, junto a Ibáñez y Perón, el "Pacto del ABC".

Ante el silencio de Vargas, Descartes no se desanimó y continuó escribiendo sus columnas. Pero, al no obtener una respuesta positiva, decidió abandonar la prédica periodística. 
Transcurridos 10 meses Descartes volvió al "periodismo de estadista", con un solo y último artículo pero en esta ocasión, fue con el fin de informar al mundo que la política exterior argentina incursionaría por "Nuevos Rumbos".

En suma, la decisión de instrumentar el "periodismo de estadista", por parte del presidente Perón, a través de su apelativo Descartes buscaría difundir a nivel nacional y, sobre todo, internacional los alcances auspiciosos que el "justicialismo" había alcanzado y, de modo especial, incorporar a su proyecto a Latinoamérica.

\section{REFERENCIAS BIBLIOGRÁFICAS}

Argentina: 1949 - 1955. Buenos Aires, Argentina: Grupo Editor Latinoamericano, 1994 CARNEIRO, G. Lusardo. O último caudillo. V. II. Botafogo, Brasil: Editora Nova Fronteira, 1978.

BOHOLASVSKY, E. Los ananás de Evita o el extraño caso de los peronistas brasileños (1945 1957). In: J. Bretona y E. Bohoslavsky (Ed.). Circule por la derecha. Percepciones, redes y contactos entre las derechas sudamericanas, 1917 - 1973, p. 170-191. Los Polvorines, Argentina: UNGS, 2016.

CHAVEZ, F. (Selección y Prólogo). Tercera posición y Unidad latinoamericana. Buenos Aires, Argentina: Biblos, 1985.

DÍAZ, C. Descartes, un singular periodista. En Red de Estudios del Peronismo. Actas del VI Congreso de Estudios sobre el Peronismo, 2019a , p. 1-23. Recuperado de

http://redesperonismo.org/articulo/descartes-un-singular-periodista

DÍAZ, C. De qué libertad se habla: La Razón de mi vida censurada en julio, 2019b. Recuperado de http://www.revistamovimiento.com/wp-

EEUU. Revista Movimiento, content/uploads/2019/07/Movimiento-14.pdf

FERNÁNDEZ BARAIBAR, J. Un solo impulso americano. El MERCOSUR de Perón. Buenos Aires, Argentina: Fondo Editorial Simón Rodríguez, 2005.

FERRÉ, M. (2015). Perón y la alianza argentino-brasileña. Córdoba, Argentina: Ediciones del Corredor.

GOLDSTEIN, A. (2017a). Prensa tradicional y liderazgos populares en Brasil. Raleigh N. C., Estados Unidos: A Contracorriente.

GOLDSTEIN, A. Geraldo Rocha: un jagunço bahiano entre Vargas y Perón. XVI Jornadas Interescuelas. Departamentos de Historia, agosto, 2017b. Mar del Plata, Argentina

GOLDSTEIN, A. Populismos clásicos e intermediarios de la prensa en Argentina y Brasil. En C. Díaz (Presidencia), II Jornadas "La comunicación está de historia", noviembre, 2016. La Plata, Argentina.

MÁRQUEZ, N. Perón el fetiche de las masas. Biografía del dictador más polémico de Argentina. Caba, Argentina: Grupo Unión, 2015.

PAZ, H. (1999). Memorias. Vida pública y privada de un argentino en el siglo XX. Buenos Aires, Argentina: Planeta. 
PELAZAS, M. Principios y límites de la democracia: Un estudio acerca del diario Democracia (Diciembre 1945-Enero 1947) (tesis de maestría). Universidad Nacional de Tres de Febrero, Buenos Aires, Argentina, 2012.

PERÓN, J. D. Obras Completas. Tomo XVI, Buenos Aires, Argentina: Docencia, 1999.

PERÓN, J. D. La Hora de los pueblos. Buenos Aires, Argentina: Norte, 1968.

PLOSTKIN, M. Mañana es san Perón. Buenos Aires, Argentina: Sudamericana, 1993.

LLAMBÍ, B. Medio siglo de política y diplomacia. Buenos Aires, Argentina: Corregidor, 1997.

RAPOPORT, M.; SPIGUEL, C. Estados Unidos y el peronismo. La política norteamericana en la.

\begin{abstract}
Notas
${ }^{1}$ Agradezco la valiosísima colaboración de dos colegas y amigos: a la Dra. Ada Machado da Silveira por el obsequio de bibliografía en portugués, primordial para este estudio. Así como la ayuda imprescindible en la traducción. Similar tarea me prestó el Dr. Javier Balsa, sumada su atenta lectura del borrador. Por supuesto, queda eximido de los errores aquí cometidos. Mi reconocimiento a Melina Gords y el Lic. Lucas Casado, quienes a raíz de mi ceguera fueron los encargados de leerme bibliografía -la primera- y el corpus -el segundoIncluyo en mi reconocimiento al personal de la biblioteca de la H. Cámara de Senadores de la Legislatura de la Provincia de Buenos Aires. Por último, agradezco especialmente, a mi amigo Hugo Narbaitz por el regalo de un ejemplar de Descartes $-1^{\circ}$ edición 1951 -

${ }^{2}$ Se halla en elaboración un artículo en clave comparada de ambos presidentes ejerciendo el "periodismo de estadista".

${ }^{3}$ Se recopilaron en formato libro publicaciones parciales de las columnas. Seguramente habrían decidido su publicación dada la aceptación que tenían en los lectores. Así aparecieron libros conteniendo 30 y 50 artículos (1951), 60 y 70 (1952) y la definitiva con 89 (1953).

${ }^{4}$ Se han dado casos en medios audiovisuales, como el del gobernador, A. Cafiero (1987-1991) en Argentina, H. Chávez (1999-2013), en Venezuela, entre otros.

${ }^{5}$ Carneiro (1978, p. 328) sostiene que Vargas recibió allí a una comisión técnico financiera de los EEUU encabezada por Nelsón Rockefeller, e hizo lo propio con enviados de Perón, H. Quijano (vicepresidente argentino); J. F. Velazco (gobernador de Corrientes); M. Miranda (Consejero económico).

${ }^{6}$ Para comprender la búsqueda de influencia a nivel internacional, la Subsecretaría de Informaciones, (11/3/1952) había elaborado la 'nómina de diarios, revistas y diarios que colaboraban con la difusión de la obra justicialista' en Brasil: "A Tribuna, A Voz Trabalhista, O' Agrario, Gazeta do Povo, O Radical, Diario Trabalhista, O Mundo, Correio da Noite, A Cruz, Diario Popular, A Vanguardia, A Noite, Correio do Povo" (Goldstein, 2016, p. 5).

${ }^{7}$ G. Carneiro (1978, p. 441) reproduce la respuesta del presidente brasileño a su embajador: "'Ah! Sr. Lusardo, Sr Lusardo! con esos milicos no se juega!' Es la primera vez que cuento esto. Vargas tenía miedo de la reacción de los militares brasileros".

${ }^{8}$ Se refiere al acuerdo firmado por los tres países el 25/5/1915 en Buenos Aires.

${ }^{9}$ El columnista [Descartes] volvió sobre este tema a fines de enero de 1952, cuando citó supuestos planes estadounidenses con relación al Canadá como prueba de que los países latinoamericanos debieran unirse para protegerse de los EEUU". (RAPOPORT Y SPIGUEL, 1994, p. 282).

${ }^{10}$ Repárese en que este artículo es considerado equivocadamente, por muchos estudiosos, la última colaboración de Descartes, incluidas las Obras Completas de Perón (1999)

${ }^{11}$ Según Carneiro (1978, p. 433), biógrafo de Lusardo, Getulio engañó a su interlocutor pues no cumpliría con su palabra.
\end{abstract}


Original recebido em: 05 de janeiro de 2020

Aceito para publicação em: 03 de abril de 2020

César Luis Díaz

Doutor em Comunicação pela Universidad Nacional de La Plata (UNLP). Pós-doutor em Comunicación, Medios y cultura pela UNLP. Diretor do Centro de Estudios en Historia/ Comunicación/ Periodismo/ Medios (CEHICOPEME) FPyCS. UNLP. Membro do Consejo

Directivo del Instituto de Investigación en Comunicación (IICOM) FP y CS. UNLP.

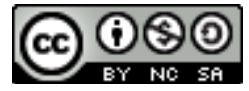

Esta obra está licenciada com uma Licença

Creative Commons Atribuição-NãoComercial-CompartilhaIgual 4.0 Internacional 